\title{
IMPROVED CORROSION RESISTANCE, MECHANICAL AND WEAR BEHAVIORS OF PARTICULATE COMPOSITE COATING OF STEEL PIPELINE FOR MARINE ENVIRONMENT
}

\author{
I.Y. Suleiman ${ }^{1 *}$, C. S. Obayi ${ }^{1}$, K. Muazu ${ }^{2}$, A. T. Mohammed ${ }^{3}$ \\ ${ }^{1}$ Department of Metallurgical and Materials Engineering, University of Nigeria, \\ Nsukka, Nigeria \\ ${ }^{2}$ Department of Pilot Plant and Fabrication, National Research Institute for Chemical \\ Technology, Zaria, Nigeria \\ ${ }^{3}$ Department of Mechanical Engineering, Waziri Umaru Federal Polytechnic, \\ Birnin Kebbi, Nigeria
}

Received 07.06.2020

Accepted 29.09.2020

\begin{abstract}
The use of agricultural wastes, which are cost-effective and environmentalfriendly materials as composites coating, is growing fast in various engineering fields. This research investigates the possibility of improving corrosion resistance, mechanical, and wear behaviors of particulate composite coating of steel pipeline with zinc alloys reinforced with groundnut shell ash (GSA) for the marine environment. Different weight percentages of $5,10,15,20$, and $25 \mathrm{wt} . \%$ GSA of particle size $75 \mu \mathrm{m}$ were used for the coatings. The groundnut shell ash was characterized by X-ray fluorescent (XRF). The morphology of the steel pipeline before and after coatings was studied using scanning electron microscope/Energy Dispersive Spectroscopy (SEM/EDS). The XRF results revealed that calcium oxides $(\mathrm{CaO})$, silica $\left(\mathrm{SiO}_{2}\right)$, alumina $\left(\mathrm{Al}_{2} \mathrm{O}_{3}\right)$, and iron oxide $\left(\mathrm{Fe}_{2} \mathrm{O}_{3}\right)$ being the major oxides present. The results showed that average coating thickness and hardness value were 45.50, 98.50, $99.67 \mu \mathrm{m}$, and 80.45, 108.60, 118.60 HBV for Zn$10 \mathrm{ZnO} / 0,20$, and $25 \mathrm{wt}$ \% GSA respectively. Their corresponding current corrosion $\left(i_{\text {corr }}\right)$ were $38.52,10.56$, and $2.98 \mathrm{~mA} / \mathrm{cm}^{2}$. The morphologies revealed that reinforcement with GSA protected the surface of the system analyzed. The corrosion rate of the steel pipeline of $38.52 \mathrm{~mA} / \mathrm{cm}^{2}$ values decreased to $10.56 \mathrm{~mA} / \mathrm{cm}^{2}$ and $1.98 \mathrm{~mA} / \mathrm{cm}^{2}$ for 0,20 , and $25 \mathrm{wt}$. \% GSA with the protection efficiency of $72.59 \%$ and $81.25 \%$, respectively. The wear rate improvement between $0-25$ wt. $\%$ GSA was $49.75 \%$. The work established $\mathrm{Zn}-10 \mathrm{ZnO} / \mathrm{GSA}$ composite coating on steel pipeline can improve the corrosion resistance, hardness, and wear rate of the studied steel pipeline coated.
\end{abstract}

${ }^{*}$ Corresponding author: I.Y. Suleiman, onoruoizadnjumas@yahoo.co.uk 
Keywords: Corrosion; steel pipeline; groundnut shell ash; wears; hardness; morphologies.

\section{Introduction}

Zinc coatings have a long history in the corrosion protection, wear resistance, decorative quality, conductivity, and the properties of zinc and zinc coatings have been thoroughly reviewed by researchers $[1,2]$. The process is usually employed to prepare thin layers of materials, including metals, alloys, semiconductors, and conductive polymers, in order to change the properties of the objects. The lifetimes of these materials are often limited due to their operating environments and other external conditions. Most metallic materials are expensive; it is, therefore, important to protect these materials as much as possible in order to extend their lifetimes. The interfaces of most of these materials may become damaged because of their atomic structures, and the surfaces of certain materials might contain susceptible sites, which results in them being easily affected by external, for example, environmental factors [3, 4]. Zinc coatings are obtained either from cyanide, non-cyanide alkaline or acid solutions. Because of the high cost and pollution associated with cyanide, deposition from other baths such as sulphate, chloride, and mixed sulphate-chloride baths are gaining importance as being carried out by [4]. Because of this, there is a need to source materials that are cost-effective and both human and environmentally friendly [4].

The essence of corrosion protection afforded by metal coatings is basically that of an environmental barrier. Its effectiveness is determined mainly by the thickness of the coating and its ability to resist attack from the environment where it finds itself $[4,5]$. It has been established that good deposition depends mainly on the nature of the bath constituents. Since a plating bath contains conducting salts, complexing agents, and metal ions, and these complexing agents influence the deposition process, solution properties, and structure of the deposits. The temperature, $\mathrm{pH}$, nature of anion, and other additives in the medium [6].

Steel pipeline is an important material being used in chemical industries, petrochemical, oil and gas, nuclear, and so on. Pipelines have been used because of their availability, fabrication, low cost, and good tensile strength besides various other desirable properties [7]. The most weakness of the steel pipeline is its susceptibility to corrosion, hardness, and wears degradation when exposed to harsh chemical environments of acids, transportation of oil and gas, and wears [8].

The corrosion of pipelines is a major challenge in the oil and gas industries. A large amount of money is being used to prevent corrosion, and a different approach to combat this problem had been used. Methods used in combating this problem include cathodic protection, coating, materials selection, and design. Among these methods, a coating is one of the common corrosion prevention methods in this area. However, most of the surface coatings used to combat the pipeline corrosion is external. A recent development in the field of the surface coating was co-deposition, and a co-deposition can be used to combat both internal and external corrosion of steel pipeline $[9,10]$. 
Many researched works on these areas include the following: $\mathrm{Zinc}-\mathrm{TiO}_{2}$ nanoparticles coating on mild steel and coating using chloride electrolytic, and the coating shows improved corrosion resistance when simulated in water [10, 11]. The report also showed that better corrosion protection of mild steel coated with Zinc phosphate/nano $\mathrm{SiO}_{2}$ coating was obtained when simulated in the medium [12]. Investigated on the enhanced coating of $\mathrm{Zn}-\mathrm{Ni}-\mathrm{Al}_{2} \mathrm{O}_{3}$ nanoparticles coating on mild steel using solelectroplating techniques, and better results were obtained by [13]. The study of the codeposition of $\mathrm{Zn}-\mathrm{Ni}-\mathrm{SiO}_{2}$ composites coating on mild steel was investigated, and the results look promising in the protection of the material [14]. It was also reported that the coating of Zinc with fly ash on mild steel was successful. Their results showed that the incorporation of fly ash increased the hardness of the coating. Zinc fly ash composite coating has a better anticorrosion property on mild steel substrate than pure zinc coating as in their conclusion [15]. The surface characterization, corrosion, and mechanical properties of polyester-polyester/snail shell powder coatings of steel pipeline for naval applications were also investigated. The reported better corrosion protection of pipelines when coated with polyester/snail shell powder. From the literature, it had been established that varying the composition of the agricultural wastes and changing the bath temperature, $\mathrm{pH}$ and so on make the use of zinc plating is promising.

The ever-increasing demand for low-cost materials and environmentally friendly motivated the interest towards production and utilization of using groundnut shells ash as co-deposition materials. Groundnut shell ashes are affordable, environmentally friendly, cost-effective means of converting wastes to wealth, and groundnut shells can be found in every part of Nigeria in particular and the world in general. It is easy to harness and suitable for aquatic and non-aquatic environments which can be explored for industrial manufacture of parts in automobiles for marine and other environments.

In this study, an attempt was made to develop a compactable and structural modified coating that will work against corrosion, wear, and mechanical deteriorations with the use of $\mathrm{Zn}-10 \mathrm{ZnO} / \mathrm{Groundnut}$ shell powder was carried out and simulated in the marine environment for industrial applications.

\section{Experimental}

\section{Materials}

The low carbon steel pipeline of $60 \mathrm{~mm}$ with inner and outer diameters of $20 \mathrm{~mm}$ and $24 \mathrm{~mm}$ was sourced from Ajaokuta Steel and was used as a substrate. Pure zinc anode was a sourced Metallurgical and Materials Engineering Laboratory. Groundnut shells (Arachis hypogaea) were sourced from Nsukka Market, Nigeria. The chemical analysis of the steel pipeline is being presented in Table 1 was used as a cathode substrate. Zinc sheets of $40 \mathrm{~mm}$ by $30 \mathrm{~mm}$ by $2 \mathrm{~mm}$ were prepared as anodes and was commercially 99.99\% pure zinc. The surface preparation was carried out using different emery paper, cleaned with distilled water, pickled and activated with $10 \% \mathrm{HCl}$ at a temperature of $30^{\circ} \mathrm{C}$ for $10-15 \mathrm{~s}$ and followed by rinsing in deionized water 
Table 1. Chemical composition of the steel pipeline

\begin{tabular}{ll}
\hline Metal Elements & wt.\% \\
\hline $\mathrm{C}$ & 0.170 \\
$\mathrm{Si}$ & 0.153 \\
$\mathrm{Mn}$ & 0.630 \\
$\mathrm{P}$ & 0.020 \\
$\mathrm{Cu}$ & 0.040 \\
$\mathrm{Al}$ & 0.039 \\
$\mathrm{~S}$ & 0.010 \\
$\mathrm{Cr}$ & 0.010 \\
$\mathrm{Ni}$ & 0.020 \\
$\mathrm{Mo}$ & 0.010 \\
$\mathrm{~W}$ & 0.088 \\
$\mathrm{Fe}$ & Balance \\
\hline
\end{tabular}

Preparation of groundnut shell ash (GSA)

The collected groundnut shell was washed and dried in the sun for three days. It was then calcined to a temperature of $700-900^{\circ} \mathrm{C}$ using the muffle furnace. The sample was then ground into fine ash powder using a grinding machine. The GSA was sieved using a set of sieves arranged in descending order of fineness, and particle size analysis was carried out in accordance with BS 1377:1990 [16]. A sieve of $75 \mu \mathrm{m}$ was used to sieve the powder before being stored in a free moisture glass container. Quantitative analysis using an X-ray diffractometer equipped with monochrome and a Rietveld refinement software, TOPASTM, was used to analyse the groundnut shell ash.

\section{Experimental Design}

The compositions stated in table 2 were dissolved in four (4) liters container to prepare the solution two days prior to the experiment before the addition of groundnut shell ash. The solution was constantly agitated in the container to ensure the proper blending of bath composition. Four 500-ml beakers were used to share $2 \mathrm{~L}$ out of the $4 \mathrm{~L}$ bath composition. The parameters used for the deposition were: voltage of $5 \mathrm{~V}$, the current density of $1.0 \mathrm{~A} / \mathrm{cm}^{2}$, and 25 minutes deposition time, as reported by [17]. The coating formulated designed bath composition of Zn-10ZnO-xGSA ( $\mathrm{x}=0,5,10,15,20$, and 25 wt.\%) was also presented in table 3. Four (4) samples each of the formulation were produced and used for the test, making a total of twenty-four (24) samples. The $\mathrm{pH}$ of the bath solution was kept constant at 4.5 and adjusted by the addition of $\mathrm{NaOH}$. After electrodeposition, the coated samples were rinsed in distilled water for $5 \mathrm{~s}$ and dried at room temperature. 
Table 2. Bath Composition of Zn-10ZnO.

\begin{tabular}{lc}
\hline Composition & Mass concentration, g/L \\
\hline Zinc Chloride & 100 \\
Ammonia Chloride & 30 \\
Boric Acid & 10 \\
Thiourea & 5 \\
Zinc oxide & 10 \\
Groundnut shellell ash (GSA) & $0-25$ \\
\hline
\end{tabular}

Table 3. Bath designed composition of Zn-10ZnO-GSA.

\begin{tabular}{llcc}
\hline Sample order & Matrix Sample & Time of deposition (minutes) & Current $\left(\mathrm{A} / \mathrm{cm}^{2}\right)$ \\
\hline 1 & Zn-10ZnO & 25 & 1.0 \\
2 & Zn-10ZnO-5GSA & 25 & 1.0 \\
3 & Zn-10ZnO-10GSA & 25 & 1.0 \\
4 & Zn-10ZnO-15GSA & 25 & 1.0 \\
5 & Zn-10ZnO-20GSA & 25 & 1.0 \\
6 & Zn-10ZnO-25GSA & 25 & 1.0 \\
\hline
\end{tabular}

Determination of Coating thickness

The thicknesses of the substrate were determined using coating thickness gauge machine YUWESE EC-770 model BC. An average of three points was used to obtain coating thickness.

\section{Microhardness measurement}

A digital portable hardness tester was used to determine the hardness values of the materials under investigation. A load of $30 \mathrm{~kg}$ was applied to the sample at three different points for 10 seconds each. The mean values obtained were used to determine hardness values. About three readings were taken at different locations of the substrates, as described by Suleiman et al. [8].

\section{Wear studies}

The substrates uncoated and coated reinforced with groundnut shell ash (GSA) of from 5 to $25 \mathrm{wt}$. \% at five wt. \% intervals were examined for the wear properties. A load of $50 \mathrm{~N}$ at a speed of $1.5 \mathrm{~m} / \mathrm{s}$ with a radius of cycles of $5 \mathrm{~cm}$ was applied. The wear test depends on the type of resistance of the samples carried out. The wear rate was then calculated using equation 1 by [8].

$$
W=\frac{m}{S . F}
$$

From the above, $\mathrm{m}$ is the weight, $\mathrm{s}$ being the slip distance, and $\mathrm{F}$ being the applied load, respectively.

\section{Microstructural studies}

The elemental analysis of groundnut shell ash was carried out using X-Ray fluorescence spectroscopy (XRF). A non-destructive and very accurate test. The extent of the coating was determined using a Philips model XL30SFEG scanning electron microscope (SEM) attached with Energy dispersive spectroscopy (EDS) was used to 
investigate the elements present at various stages of the reinforcements. The studies were carried out in the materials laboratory of the University of Johannesburg, South Africa.

\section{Corrosion test}

The corrosion test was conducted on the electrochemical tester Model: CHI604E. The test was conducted in accordance with ASTM G8-96 Standard. The electrochemical consist of three electrodes: the samples were served as the working electrode, $\mathrm{Ag} / \mathrm{AgCl}$ the references electrode and the graphite rod as the counter electrode. Simulated seawater was used as the electrolyte for the corrosion analysis, and the details being presented in table 4 .

A voltage of -1.5 to $+1.5 \mathrm{mV}$ was used for the analysis. A scan rate of $2 \mathrm{mV}$ in the potential range from -0.5 to $+1.5 \mathrm{mV}$ relative to the corrosion potential $\left(\mathrm{E}_{\mathrm{corr}}\right)$ was used for both anodic and cathodic potentiodynamic polarization curves. The polarization resistance of the sample was computed using equation 2 . From equation $2, i_{\text {corr }}$ was then computed.

$$
R_{P}=\frac{\beta_{a} \beta_{c}}{2.3 i \operatorname{corr}\left(\beta_{a}+\beta_{c}\right)}
$$

Where: $\beta_{\mathrm{a}}$, is the anodic constant, $\beta_{\mathrm{c}}$ the cathodic constant, and $i_{\text {corr }}$ is the current density.

Table 4. Seawater used according to ASTM D1141-98 composition.

\begin{tabular}{|c|c|c|}
\hline Components & & Concentration, g/L \\
\hline Sodium Chloride & $(\mathrm{NaCl})$ & 24.53 \\
\hline Magnesium Chloride & $\left(\mathrm{MgCl}_{2}\right)$ & 5.2 \\
\hline Sodium Sulphate & $\left(\mathrm{Na}_{2} \mathrm{SO}_{4}\right)$ & 4.09 \\
\hline Calcium Chloride & $\left(\mathrm{CaCl}_{2}\right)$ & 1.16 \\
\hline Potassium Chloride & $(\mathrm{KCl})$ & 0.695 \\
\hline Sodium Bicarbonate & $\left(\mathrm{NaHCO}_{3}\right)$ & 0.201 \\
\hline Potassium Bromide & $(\mathrm{KBr})$ & 0.101 \\
\hline Boric acid & $\left(\mathrm{H}_{3} \mathrm{BO}_{3}\right)$ & 0.027 \\
\hline Strontium Chloride & $\left(\mathrm{SrCl}_{2}\right)$ & 0.0025 \\
\hline Sodium Fluoride & $(\mathrm{NaF})$ & 0.003 \\
\hline
\end{tabular}

\section{Results and discussions}

Groundnut shell ash elemental Analysis

The results revealed by the elemental analysis presented in Table 5. From the table, the groundnut shell ash contains calcium oxide content of $79.36 \%$, silica of $10.91 \%$, alumina of $4.23 \%$, iron oxide of $2.16 \%$, magnesium oxide of $1.72 \%$, potassium oxide of $0.38 \%$, titanium oxide of $0.60 \%$, and the remaining balance was lost on ignition (LOI) respectively. With the high percentage of calcium oxide and silica in the groundnut shell ash, it means that the groundnut shell ash is classified as basic in nature. The high percentages of calcium oxide in the groundnut shell ash promote its refractoriness and thermal stability. The presence of calcium oxide and silica in the groundnut shell ash, 
according to the work of [14], showed that refractory materials had been used as electrode deposition.

Table 5. The XRF Analysis of groundnut shell ash.

\begin{tabular}{ll}
\hline Oxides & wt.\% \\
\hline $\mathrm{CaO}$ & 79.36 \\
$\mathrm{SiO}_{2}$ & 10.91 \\
$\mathrm{Al}_{2} \mathrm{O}_{3}$ & 4.23 \\
$\mathrm{Fe}_{2} \mathrm{O}_{3}$ & 2.16 \\
$\mathrm{MgO}$ & 1.72 \\
$\mathrm{~K}_{2} \mathrm{O}$ & 0.38 \\
$\mathrm{TiO}_{2}$ & 0.60 \\
$\mathrm{SO}_{3}$ & 0.01 \\
$\mathrm{CO}_{3}$ & 0.2 \\
$\mathrm{LOI}$ & 0.54 \\
\hline
\end{tabular}

\section{Coating thickness}

The coating thicknesses of the substrates with zinc oxide/GSA were presented in figure 1 .

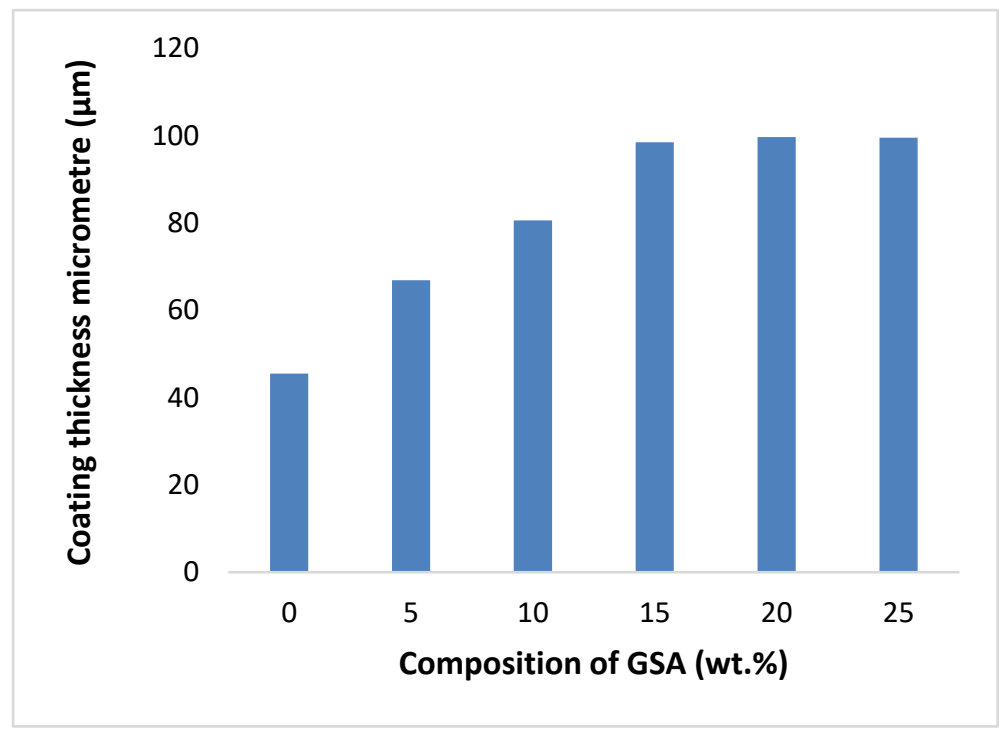

Fig. 1. Thickness after coating against GSA.

The figure showed that as the weight of groundnut shell ash increases, the coating thickness also increases. The coating thickness of the samples increased from 0 to 45.50 $\mu \mathrm{m}$ at 5 wt. $\%, 66.90 \mu \mathrm{m}$ at $10 \mathrm{wt} . \%, 71.60$ at $15 \mu \mathrm{m}$ wt. $\%, 98.50 \mu \mathrm{m}$ at $20 \mathrm{wt} . \%$, and $97.40 \mu \mathrm{m}$ at $25 \mathrm{wt} . \%$ GSA respectively. The highest coating thickness was obtained at steel pipeline-Zn-10ZnO-GSA-20 wt. \% GSA with values of $98.50 \mu \mathrm{m}$. The ultimate coating thickness was recorded at $20 \mathrm{wt}$. \% GSA may be attributed to the bath suspension attaining greater dissolution of particles at this temperature. At $20 \mathrm{wt}$. \% GSA, there was a decline in the coating thickness of the samples and might due to the fact that the 
reactions in the bath tend to dissociate at that reaction temperature and instead of the substrate to adsorb, but it desorbed. It implied that $20 \mathrm{wt}$ \% GSA was the ultimate of the filler in the $\mathrm{ZnO} / \mathrm{GSA}$ that can produce a quality coating. This relationship is similar to the findings of $[18,19]$.

\section{Hardness values}

The hardness values of the coating were presented in Figure 2. The figure revealed that the hardness of coated substrates increased as the weight percent of GSA increases from $5-20 \mathrm{wt}, \%$, and dropped at $25 \mathrm{wt}$. \% respectively. The hardness values increase to maximum values at $25 \mathrm{wt}$. \% of GSA at bath temperatures observed. This increase in the hardness could be attributed to the higher hardness of the ceramic materials in the groundnut shell ash such as $\mathrm{CaO}, \mathrm{SiO}_{2}, \mathrm{Al}_{2} \mathrm{O}_{3}, \mathrm{~K}_{2} \mathrm{O}$, and so on when compared to uncoated steel pipeline. The high hardness values obtained at $\mathrm{Zn}-\mathrm{ZnO}-25 \mathrm{wt}$ \% GSA could be attributed to the close-packed and smaller structure obtained in the morphologies of the coating presented in figure 5. The smaller the grain structure, the more stress fields interact with the dislocation planes according to the Orowon mechanism. This effect led to the hindrance movement of dislocation and more strain hardening effect according to the findings of [20].

In general, the calcium oxide, silica, alumina compositions in the groundnut shell ash contributes immensely to the hardness property of the coatings at $25 \mathrm{wt} \%$ GSA hence, good and adhered coating were obtained, which were free from defects, crack with good hardness behaviour. An increase in hardness values that were obtained could be attributed to the fact that the bath slurry may be too thick for easy deposition, and this makes it difficult for the flow of electron during the electrodeposition and similar to works reported by [21].

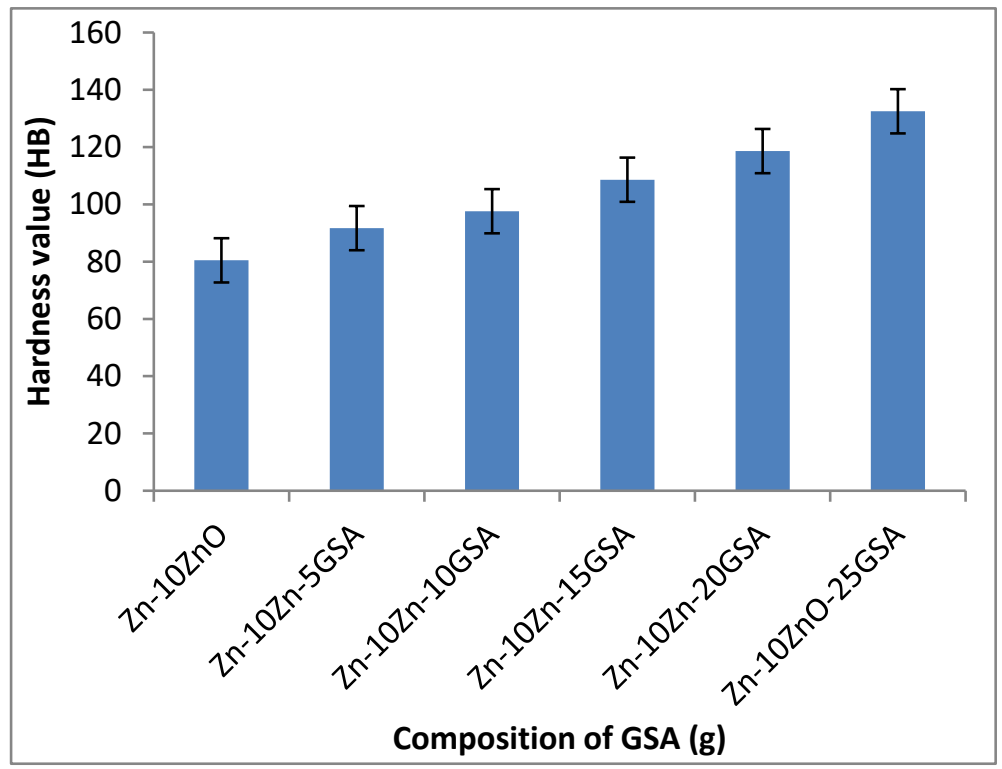

Fig. 2. Variation of hardness values with weight addition of GSA. 


\section{Morphological analysis}

The microstructure of the samples obtained from the scanning electron microscopy (SEM) and energy dispersive spectroscopy (EDS) were presented in figures 3-5. From the figures, it was observed that there were great microstructural differences in the microstructure of the steel pipeline (control), $\mathrm{Zn}-\mathrm{ZnO} / 20$ and $\mathrm{Zn}-\mathrm{ZnO} / 25$ wt. \% GSA respectively. Figure 3 showed the morphology of the steel pipeline before electrodeposition, and was observed that there was no structure formed on the steel pipeline before deposition. The image only revealed the cutting surface of the sample with an abrasive cutter. The SEM image of the $\mathrm{Zn}-10 \mathrm{ZnO} / 20$ coated was presented in figure 4. Comparing figures 4 and 5 with $\mathrm{Zn}-\mathrm{ZnO} / 25 \mathrm{wt}$. \% GSA coating on steel pipeline, figure 5 shows a random distribution of the particles in a different form. The image without groundnut shell ash addition shows little porosity, and the crystals were not well defined. While the addition of groundnut shell ash as an additive results in the change of the texture of the coating. The structure formed was closely packed together, tough, strong, and the surface is hard. The groundnut shell ash acts as an adsorbate, which increases in the surface area of the particles during electrodeposition. The coated samples were also free from cracks, cavities, and made the electrodeposition successful and supported by [14]. Energy dispersive spectroscopy (EDS) revealed the microanalysis of the structure before and after deposition. The EDS of the steel pipeline revealed iron has a high peak followed by carbon, which supported the fact that the steel pipeline used in this research was low carbon steel. While EDS of the electrodeposition presented in figure 4 revealed that of $\mathrm{Zn}-10 \mathrm{ZnO}$ without groundnut shell ash elements. From the figure, Zinc is the dominant element, and this showed that the deposition was zinc-based coating. Figure 5 showed the EDS of Zn-10ZnO-GSA. From the figure, EDS revealed Zn, O, Fe, $\mathrm{C}, \mathrm{Al}, \mathrm{Si}, \mathrm{K}, \mathrm{Ca}$, and the presence of $\mathrm{Al}, \mathrm{Si}, \mathrm{K}, \mathrm{Ca}$ in the $\mathrm{EDS}$, which is evidence that the GSA was used in the coating and also supported the findings of [19].
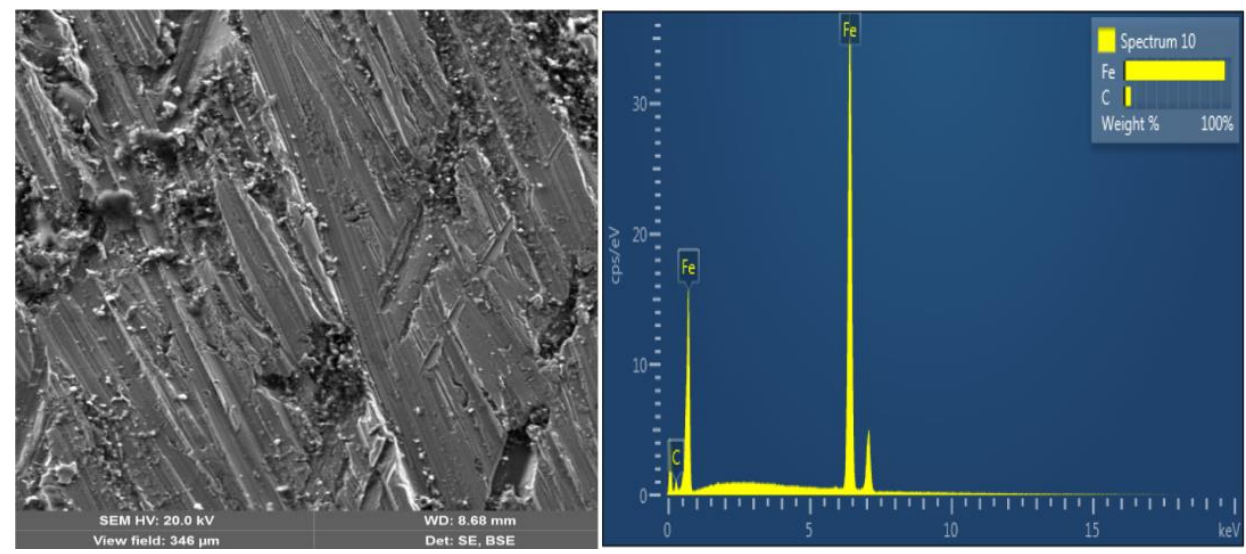

Fig. 3 SEM/EDS of steel pipeline before deposition. 


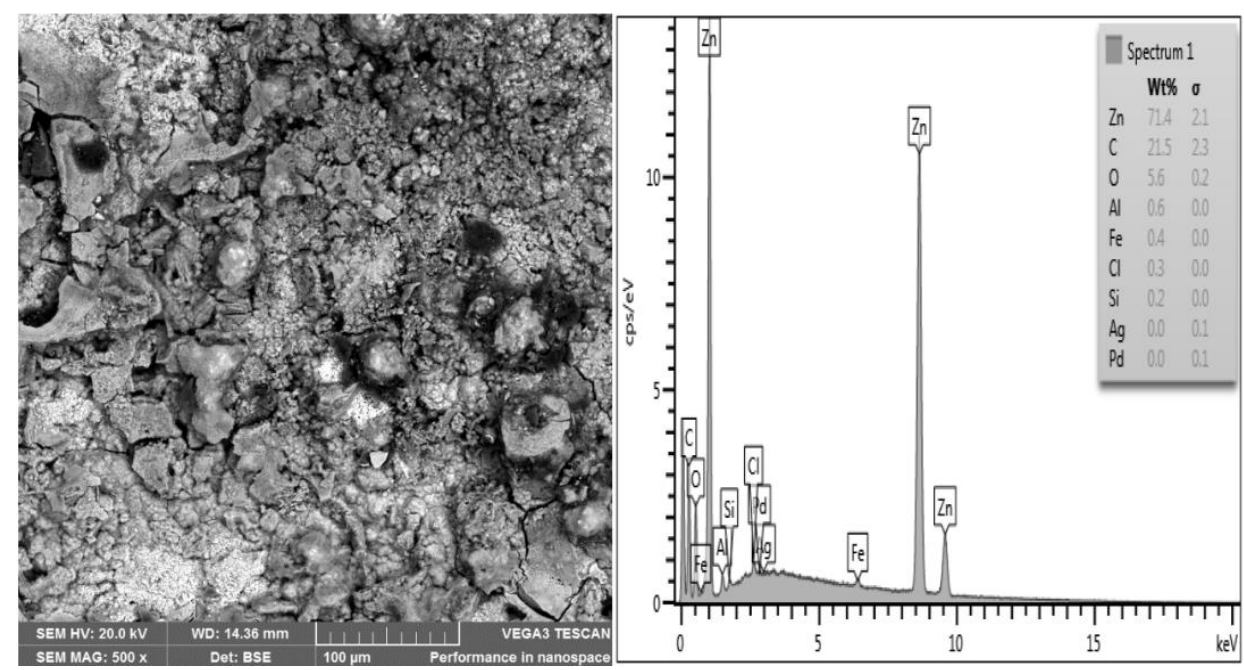

Fig. 4 SEM/EDS of steel pipeline with deposition of $\mathrm{Zn-10ZnO.}$
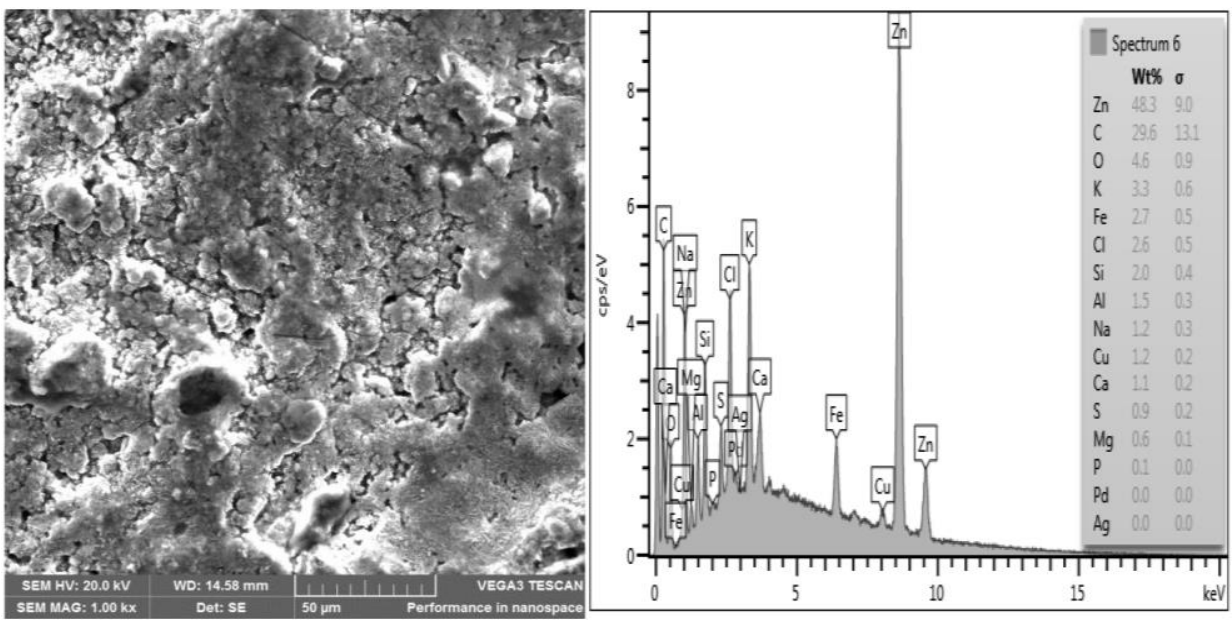

Fig. 5 EDS steel pipeline with deposition of Zn-10ZnO/25g GSA.

Tafel Test

The samples were evaluated for corrosion behavior in seawater. The polarization curves for steel pipeline, steel pipeline $/ \mathrm{Zn} / 10 \mathrm{Zn} / 20 \mathrm{wt} \%$ and steel pipeline/Zn/10Zn/25 wt. \% GSA were shown in figure 6. It was observed that the open circuit potential was shifted to more positive values, which indicates that the coating gives protection. As the weight of groundnut increases, the current density decreases at the same potential. The decrease in the corrosion currents obtained for the coated samples could be attributed to the microstructures showed in the previous figures 4-5. The microstructures had good closed morphology, and this closes up the active sites, which could trigger corrosion on the samples. Table 6 presented the potential, polarization resistance, and current density of the samples. The $i_{\text {corr }}$ of the steel pipeline as control, steel pipeline coated in 15 and 20 
wt. \%GSA respectively were $38.52,10.56$, and $1.98 \mathrm{~mA} / \mathrm{cm}^{2}$, respectively. The least corrosion current density of 1.98 for pipeline $/ 25 \mathrm{wt} \%$ GSA is about 19.45 times than steel pipeline without coating in zinc/GSA in seawater. This confirmed the microstructural analysis presented in figures 3-5. The steel pipeline coated with $\mathrm{ZnO} / 25$ wt. $\%$ GSA is better in seawater applications, and their $i_{\text {corr }}$ were improved according to $[14,18,22]$. The groundnut shell ash composition highly influenced the corrosion current density. The protection efficiency increases from $72.59 \%$ at $20 \mathrm{wt} \%$ GSA to $81.25 \%$ at 25 wt. \% GSA composition.

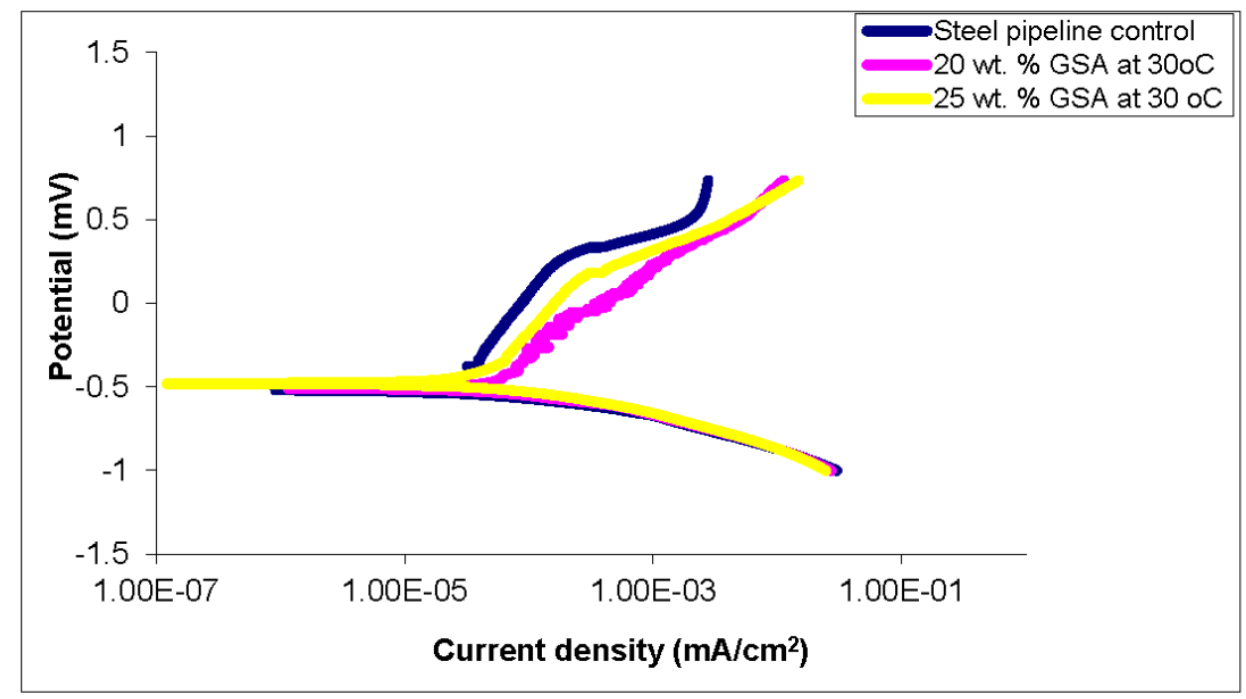

Fig. 6. Polarization curves for steel pipeline control, 20 and 25 wt. \% GSA.

Table 6. Tafel polarization parameters for coated and uncoated low carbon steel in seawater at different reinforcements.

\begin{tabular}{lcccc}
\hline Sample & $\mathrm{E}_{\text {corr }}(\mathrm{mVvs.} \mathrm{SCE})$ & $\mathrm{i}_{\text {corr }}\left(\mathrm{mA} / \mathrm{cm}^{2}\right)$ & $\beta_{\mathrm{c}}(\mathrm{V} / \mathrm{dec} a d e)$ & $\mathrm{B}_{\mathrm{a}}(\mathrm{V} /$ decade $)$ \\
\hline Steel pipeline & -511.5 & 38.52 & 489.9 & 108.3 \\
10Zn/20 wt.\% GSA & -563.6 & 10.56 & 389.7 & 85.8 \\
10/Zn/25wt.\% GSA & -592.1 & 1.98 & 367.9 & 145.7 \\
\hline
\end{tabular}

Wear analysis

In Figure 7 presented the wear behaviour of the samples from 0-25 wt. \% GSA. It was observed that the addition of GSA in the formulation decreased the wear rate. The wear rates improved as the reinforcement of GSA increases. In all, 49.75 per cent improvement of wear rate was obtained at $25 \mathrm{wt}$ \% GSA addition over that of the uncoated sample. The reduction could be attributed to GSA inclusion in the matrix of coating that acts as load-bearing constituents, fostering a better interfacial attraction within the composite [8]. Hence, the reinforcement of the GSA adhered to the coating and difficult to be removed, hence created good structure with a better wear rate [18]. 


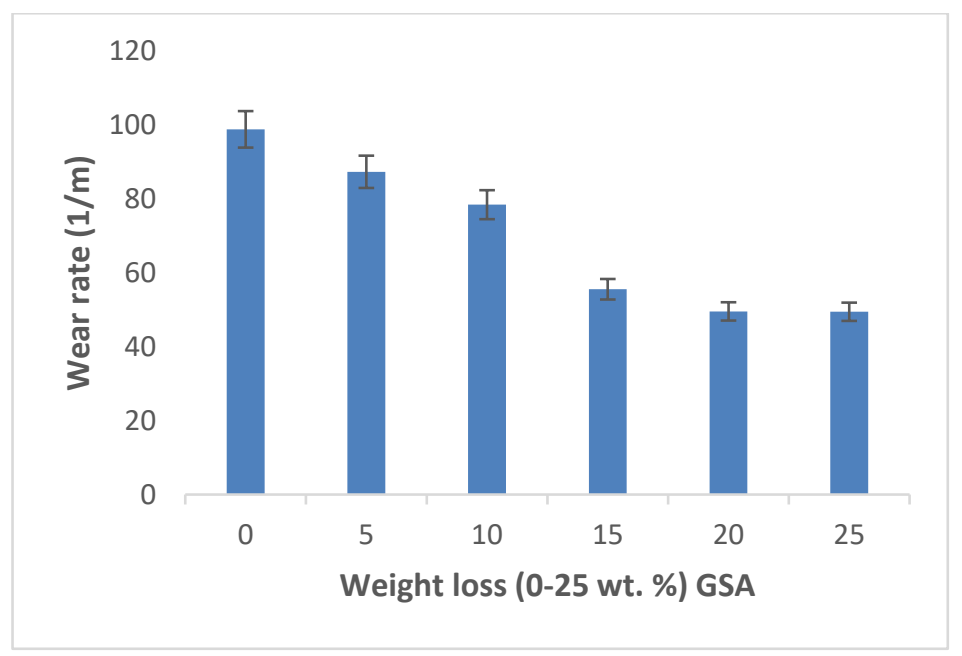

Fig. 7. The specific wear rate values for the uncoated and coated substrates.

\section{Conclusion}

From the results, the following conclusions can be drawn:

1. Coating with maximum performance was obtained at $25 \mathrm{wt} . \%$ GSA addition.

2. The groundnut shell ash deposition enhances both the surface finish, coating thickness, and the hardness of the steel pipeline with $\mathrm{Zn}-10 \mathrm{ZnO} / 0-25$ wt. \% GSA.

3. The current corrosion $\left(i_{\text {corr }}\right)$ of the steel pipeline of $38.52 i_{\text {corr }}$ values decreased to $10.56 i_{\text {corr }}$ and $1.98 i_{\text {corr }}$ for $0,10 \mathrm{Zn} / 20$ and $10 \mathrm{Zn} / 25 \mathrm{wt}$. \% GSA respectively. Also, 49.75 per cent improvement of wear rate was obtained at 25 wt. \% GSA coatings compared to control.

4. The maximum current corrosion protection efficiency obtained in this work were $72.59 \%$ and 81.25 wt. \% GSA of $\mathrm{Zn}-10 \mathrm{ZnO}-20$ and 25 wt. \% GSA respectively.

\section{Acknowledgement}

The authors are thankful to the staff of the Department of Metallurgical and Materials Engineering, University of Nigeria, Nsukka. Also grateful to the staff of Tshwane University of Technology, Pretoria South Africa for some laboratory analysis in general.

\section{References}

[1] O. K. Ole, A. Forsgren: Corrosion Control Through Oranic Coatings, CRC Press, Taylor \& Francis Group, (2017) p. 183.

[2] D. A. Bayliss, D. H. Deacon: Steelwork Corrosion Control, $2^{\text {nd }}$ ed. New York: Taylor \& Francis, (2002) p.23.

[3] H. AL-Esary, K. S. Ryder, A. P. Abbott: University of Leicester, (2015) 24-45.

[4] Y. Takeshita, T. Sawada, T, Handa, Y. Watanuki, T. Kudo: Prog Organic Coat, 75 (2012) 584-589. 
[5] C. Mou, X. Sen, Y. Sen: J Solid State Electrochem, 14 (2010) 2235-2240.

[6] D. Blejan, L. M. Muresan: Maters Corro, 64: (2013) 433-438.

[7] A. E. Refaey, W. Tillmann: J Weld Res Counc, 87 (2008) 113-118.

[8] I. Y. Suleiman, V.S. Aigbodion, C. S. Obayi, K. Mu'azu: Int J Adv Manuf Technol, 101 (2019) 2441-2447.

[9] C. R. Crick, I. P. Parkin: Chem Euro J, 16 (2010) 3568-3588.

[10] K. M. K. Punith, K. M. K, Venkatesha: J Chem Pharm Res, 5 (2013) 253-261.

[11] B. M. Durodola, J. A. O. Olugbuyiro, S. A. Moshood: Int J Electrochem Sci, 6 (2011) 5605-5616.

[12] M. Tamilselvi, P. Kamaraj, M. Arthanareeswari: App Surf Sci, 332 (2015) 12-21.

[13] S. Ghaziof, W. Gao: Int J Chem Mole Nucl Mates Met Eng, 9 (2015) 945-949.

[14] J. Tolumoye, P. Tuaweri Pressy, A. N. Jombor: Int J Adv Mats Sci Eng, 3 (2014) 1234-1242.

[15] C. N. Panagopulos, E. P. Georgion, A. G. Grava: J Surf Coat Technol, 24 (2009) 20436-20443.

[16] E. P. Marshall, G. P. Edward: Mater Desig, 32 (1999) 4054-4061.

[17] N. Eliaz, K. Venkatakrishna, H. A. Chitharanjan: Surf Coat Technol, 205: (2010) $1969-1978$.

[18] S. Ghaziof, W. Gao: Int J Chem Mol Nucl Mater Met Eng, 9 (2015)945-949.

[19] I. Y. Suleiman, A. S. Sani, A. T. Mohammed: Int J Adv Manu Technol, 97 (2019) 4137-4144.

[20] J. Abdul, Y. Ghulam, Q. Waheed, M. Khan, A. Yousaf, M. Rashid, M. Korai, N. Naeem, M. Ghulam: RSC Adv, 7 (2017) 31100-3110910.

[21] P. Gauiter, A. Vallee, A. Sintor, A. Etcheberry, N. Simon: Mater, 62 (2016) 6779.

[22] S. K. Tiwari, R. K. Sahu, A. K. Pramanick, S. Raghuvir: Surf Coat Technol, 205 (2011) 4960-4967.

\section{(c) (†) Creative Commons License}

This work is licensed under a Creative Commons Attribution 4.0 International License. 